\title{
Obesity, Comorbidities, and the Associated Risk among Patients Who Underwent Total Knee Arthroplasty in Alberta
}

\author{
Fatemeh Baghbani-Naghadehi, PhD ${ }^{1}$ Susan Armijo-Olivo, PhD ${ }^{1,2,3}$ Carla M. Prado, RD, PhD 4 \\ Linda J. Woodhouse, PT, PhD ${ }^{1,5}$
}

\footnotetext{
${ }^{1}$ Department of Physical Therapy, Faculty of Rehabilitation Medicine, University of Alberta, Edmonton, Alberta, Canada

2 Faculty of Business and Social Sciences, University of Applied Sciences, Osnabrück, Germany

${ }^{3}$ Faculty of Medicine and Dentistry, University of Alberta, Edmonton, Alberta, Canada

${ }^{4}$ Department of Agricultural, Food and Nutritional Science, Faculty of Agricultural, Life and Environmental Sciences, University of Alberta, Edmonton, Alberta, Canada

${ }^{5}$ Department of Public Health and Community Medicine, School of Medicine, Tufts University, Boston, Massachusetts
}

\begin{abstract}
Address for correspondence Fatemeh Baghbani-Nagadehi, PhD, Department of Physical Therapy, Faculty of Rehabilitation Medicine, University of Alberta, 8205114 Street Northwest, Edmonton, AB T6G 2G4, Canada (e-mail: baghbani@ualberta.ca).
\end{abstract}

J Knee Surg

\begin{abstract}
Obesity, a common risk factor for osteoarthritis (OA), accelerates joint deterioration resulting in the need for early total knee arthroplasty (TKA). The role of obesity in the management of OA remains a controversial topic. In this study, we examined whether obesity along with other comorbidities is associated with peri/postoperative complications in patients who underwent primary unilateral TKA in Alberta, Canada. A retrospective secondary analysis was performed on data extracted from data repository of patients ( $n=15,151)$ who underwent TKA between 2012 and 2016. The sample was divided into five groups based on body mass index (BMI) classification developed by the World Health Organization. The associations between dependent variable (presence or absence of a complication or comorbidity) with the independent variables (year of surgery, age, sex, length of surgery, and BMI groups) were examined using binomial logistic regression. Results showed that obese classes I, II, and III, irrespective of other covariates, were more likely to have diabetes and pulmonary embolism $(p<0.001)$ compared with the normal BMI group. Patients with obese class III compared with the

Keywords

- obesity

- total knee arthroplasty

- osteoarthritis

- comorbidities

- complications patients in normal BMI group were more likely to have deep wound infection $(p=0.04)$. Patients with comorbidities were more likely to have a blood transfusion, infection, pulmonary embolism, and readmission. Patients in higher BMI groups or with comorbidities were more likely to experience peri/postoperative complications following TKA, though the level of risk depends on the severity of obesity. These findings may be used by health care providers to educate patients in higher BMI groups about the risks of TKA and optimize comorbidities prior to the surgery.
\end{abstract}

received

June 29, 2021

accepted after revision

December 9, 2021 (c) 2022. Thieme. All rights reserved.

Thieme Medical Publishers, Inc., 333 Seventh Avenue, 18th Floor, New York, NY 10001, USA
DOI https://doi.org/ 10.1055/s-0042-1742646. ISSN 1538-8506. 
Obesity impacts over 600 million adults around the world. ${ }^{1}$ It is associated with an elevated risk of adverse health outcomes, including cardiovascular disease, diabetes, cancer, and osteoarthritis (OA). ${ }^{2}$ The rising prevalence of obesity and its associated health risks make it a major public health issue worldwide. ${ }^{2,3}$ Obesity, a common risk factor for the onset and progression of $\mathrm{OA},{ }^{4}$ accelerates joint deterioration in patients with knee OA resulting in the need for early total knee arthroplasty (TKA). Thus, the management of OA requires an understanding of the role that obesity plays in the development and progression of end-stage knee OA. ${ }^{5}$ With the rise in demand for TKA, orthopaedic surgeons are concerned about whether patients with higher body mass index (BMI), notably BMI class III, are at an increased risk for perioperative or postoperative complications compared with other BMI groups. ${ }^{4}$

There has been an abundance of literature over the past decade that has raised concerns regarding the outcomes of TKA, including complications, in patients with obesity. ${ }^{6-10}$ These studies have consistently demonstrated increased rates of wound healing complications, superficial and deep infections, early revisions, and poor functional outcomes following TKA in patients with obesity. ${ }^{11-13}$ However, the role and importance that obesity plays in the decision to perform TKA remains under debate. ${ }^{4,14}$ This reflects a lack of general consensus about performing TKA surgery on patients with obesity. ${ }^{4}$

A literature review conducted by a workgroup of the American Association of Hip and Knee Surgeons on obesity and total joint arthroplasty concluded that most studies examining TKA in patients with obesity used different surgical procedures and postoperative care protocols, small sample sizes, and different definitions of obesity. ${ }^{4}$ The majority of previous studies did not use the World Health Organization (WHO) classification of obesity to stratify patients into subclasses of obesity; instead, they classified patients as either with obesity (BMI $\geq 30 \mathrm{~kg} / \mathrm{m}^{2}$ ) or without obesity (BMI $<30 \mathrm{~kg} / \mathrm{m}^{2}$ ). ${ }^{4}$ Moreover, patients with OA and obesity often have multiple medical comorbidities, such as diabetes and cardiopulmonary diseases. ${ }^{1}$ Many of these comorbidities have been shown to be independent risk factors for the development of joint infection and also perioperative complications. ${ }^{4}$ If the risks associated with these comorbidities have not been taken into account in the statistical analysis, they may act as confounders and affect the results of the study. Methodological approaches to adjust for comorbidities in the statistical analysis have been suggested, but they have not been consistently taken into consideration in previous studies of the association between obesity with complication. ${ }^{4,15}$ Therefore, the primary purpose of our study was to examine whether obesity using the WHO classification of BMI is associated with other comorbidities, as well as with perioperative/postoperative complications in patients who underwent TKA adjusting for putative confounders. We also examined the association between major comorbidities and complications in people who underwent primary unilateral TKA over a 5-year period (2012-2016) in Alberta, Canada.

\section{Method}

\section{Data Acquisition}

We extracted data for a retrospective cohort of patients who underwent primary unilateral TKA between January 2012 and March 2016, from a provincial database managed by the Alberta Bone and Joint Health Institute (ABJHI). Standardized care processes and consistent data collection commenced in 2009 and remain ongoing for the province. Data have been collected under the authority of the provincial Privacy Impact Analysis (PIA) agreement in place (Office of the Information and Privacy Commissioner, OIPC file no.: H2801) for all private clinics and public hospitals where TKAs are performed. Knee surgeries are performed at 12 hospitals across Alberta, Canada, and all data are sent to $\mathrm{ABJHI}$ for quality assurance purposes. The Discharge Abstract Database (DAD) is a national database that contains data captured in acute care hospitals and includes administrative, clinical, and demographic information for hospital discharges. Data from DAD were linked to the database managed by ABJHI to identify comorbidities and complications in patients. Diagnosis for morbidity and mortality and procedure coding were based on the 10th version of the International Classification of Diseases combined with the Canadian Classification of Health Intervention (ICD-10-CA/CCI).

\section{Study Sample}

We were able to identify 26,962 patients who underwent primary unilateral TKA between 2012 and 2016. Weight and height records were available for 15,151 (56.2\%) patients to calculate BMI as weight in kilograms ( $\mathrm{kg}$ ) divided by height in meter squared $\left(\mathrm{m}^{2}\right)$. Only those patients with BMI records who underwent primary unilateral TKA were included in the analysis. There were no differences in participant characteristics (i.e., mean age and sex), the rate of major comorbidities, or complications ( - Supplementary Table S1; available in the online version) between the included and excluded cohorts. Patients in the included cohort were classified into one of five groups according to the WHO classification of normal weight (BMI $\left.\leq 24.99 \mathrm{~kg} / \mathrm{m}^{2}\right)$, overweight $(25 \leq \mathrm{BMI} \leq 29.99$ $\left.\mathrm{kg} / \mathrm{m}^{2}\right)$, obese class I $\left(30 \leq \mathrm{BMI} \leq 34.99 \mathrm{~kg} / \mathrm{m}^{2}\right)$, obese class II $\left(35 \leq\right.$ BMI $\left.\leq 39.99 \mathrm{~kg} / \mathrm{m}^{2}\right)$, and obese class III (BMI $\geq 40$ $\left.\mathrm{kg} / \mathrm{m}^{2}\right){ }^{1}$ A total of 17 patients with a BMI lower than 18.5 (underweight) were included in the normal BMI group. Patients' demographic information including age, discharge date, and sex were available. Age was categorized into five groups of $<50,50$ to 59,60 to 69,70 to 79 , and $>80$ years. The discharge date was categorized by year into six groups: 2012 , 2013, 2014, 2015, and 2016. Comorbidities included diabetes, moderate or severe mental health issues, cardiac disease, pulmonary disease, circulatory/clotting disorder, dementia, renal failure, cerebrovascular disease, and moderate or severe liver disease as recorded in the database.

\section{Outcomes}

Perioperative and postoperative complications were blood transfusion, pulmonary embolism, deep wound infection, myocardial infarction, ileus, pneumonia, deep vein 
thrombosis, gastrointestinal bleeding, readmission within 30 days, and cerebrovascular accident.

\section{Statistical Analysis}

The prevalence of obesity among patients who underwent primary unilateral TKA and the incidence rate of comorbidities and complications within each of the BMI groups were determined and compared using Chi-squared testing. The association between each of the main dependent variables (a complication or comorbidity) with each of the nominal/ categorical independent variables (year of surgery, age, sex, length of surgery, and BMI groups) was examined in a univariate fashion using Chi-squared test of independence. Independent variables with $p<0.15$ were included in the full model. Model selection was performed using backward and forward stepwise regression analysis, and competing models were compared using the Akaike Information Criterion. Both stepwise forward and backward methods confirmed that the full logistic regression model was the best model (the model with all variables). Binomial logistic regression was used to determine whether the dependent variable (presence or absence of a complication or comorbidity) was associated with the independent variables (year of surgery, age, sex, length of surgery, and BMI groups). When complication was considered as a dependent variable, comorbidities were included as independent variables. Results for each dependent variable are reported as odds ratios (OR) with 95\% confidence intervals (CIs) calculated to compare the likelihood between each of the BMI groups and the normal BMI group, adjusting for all covariates of interest in the model. ${ }^{16}$ An OR of 1 (i.e., $\mathrm{OR}=1$ ) means the likelihood of the event is the same for the group of interest (high BMI) when compared with the reference group (normal BMI group). An OR $>1$ or $\mathrm{OR}<1$ suggests an increased or reduced likelihood of the event in each group of interest occurring compared with the reference group. If a $95 \% \mathrm{CI}$ for the OR includes the value of 1 , then there is insufficient evidence to conclude that there is a statistically significant difference in likelihoods for the groups. All statistical analyses were performed using R software package version 0.99.902.

\section{Results}

Patients' characteristics are presented in (-Supplementary Table S1; available in the online version). Between January 2012 and March 2016, a total of 15,151 patients who underwent TKA and had BMI records were identified, including 1,240 (8.2\%) individuals with normal BMI, 4,189 (27.6\%) overweight, 4,541 (30.0\%) obese class I, 2,839 (18.7\%) class II, and 2,342 (15.5\%) in the class III BMI groups. Overall, the mean age \pm standard deviation of the cohort was $66 \pm 9.2$ years. Unadjusted analysis showed as BMI increased, patients were more frequently younger in age and female. In total, $23.7 \%$ $(n=3,590)$ of patients who underwent TKA with BMI records had comorbidities. The most frequent comorbidities among patients were diabetes $(58.1 \%, n=2,086)$, moderate or severe mental health issues $(37 \%, n=1,329)$, and cardiac disease $(3.3 \%, n=118)$. The remaining comorbidities were pulmonary disease $(0.8 \%, n=29)$, and circulatory/clotting disorder $(0.6 \%$, $n=21)$. As BMI increased, the proportion of people with diabetes increased, with obese class-III group having the highest proportion, and differences in proportions among the groups were significant $(p<0.001)$. There were also significant differences in the proportion of people with mental health issues $(p<0.001)$, circulatory/clotting disorders $(p<0.03)$, smoking $(p<0.002)$, and alcohol abuse $(p<0.001)$ between the different BMI groups.

Results from unadjusted analysis also showed that the most frequent complications among patients were readmission $(52.8 \%, n=569)$, pulmonary embolism $(21.7 \%, n=233)$, and deep wound infection $(10.7 \%, n=115)$. The remaining complications were myocardial infarction $(4.2 \%, n=45)$, ileus $(4.0 \%, n=43)$, pneumonia $(3.3 \%, n=35)$, deep vein thrombosis (1.6\%, $n=17)$, gastrointestinal bleeding $(1.7 \%$, $n=18)$, and cerebrovascular accident $(0.1 \%, n=1)$. Patients with very low or very high BMI had a higher proportion of readmission $(p<0.001)$. As BMI increased, the proportion of people with pulmonary embolism and deep wound infection increased, with obese class-III group having the highest proportion, and differences in proportions among the groups were significant $(p<0.001)$.

Results of adjusted multiple regression analysis (-Table 2; ORs and their 95\% CIs) showed that obese classs I, II, and III were more likely $(p<0.001)$ to have diabetes compared with the normal BMI group. There was a nonsignificant ( $p=0.14$ ) trend toward a higher incidence of cardiac disease in patients with obese class III compared with the normal BMI group. Obese classes I, II, and III groups, irrespective of other covariates, compared with normal BMI group, were more likely to experience pulmonary embolism (obese class I: $p=0.004$; class II: $p=0.006$; and class III: $p<0.001)$. Patients with obese class III compared with the patients in normal BMI group were more likely to have deep wound infection $(p=0.04)$ and a trend $(p=0.10)$ of the increased likelihood of readmission (-Table 2 ).

Results of the association between comorbidities and complications (-Table 3; ORs and their 95\% CIs) showed that patients with a history of diabetes $(p<0.001)$, cardiac disease $(p<0.001)$, circulatory/clotting disorder $(p<0.001)$, mental health $(p<0.001)$, alcohol abuse $(p=0.04)$, and smoking $(p=0.002)$ were more likely to also receive a blood transfusion compared with the patients without those comorbidities. Patients with a history of diabetes $(p<0.001)$, mental health $(p<0.001)$, alcohol abuse $(p<0.001)$, and smoking $(p<0.001)$ were more likely to be readmitted to the hospital. Patients with cardiac $(p<0.001)$ and pulmonary $(p<0.001)$ diseases were more likely to have pulmonary embolism compared with patients without a history of cardiac and pulmonary disease. There was no association between deep wound infections and any of the comorbidities listed. The model did not generate odd ratios for some of the comorbidities due to the lower frequency of occurrence.

\section{Discussion}

The results of this study indicate that the obese class-III group had a higher proportion of younger patients $(<50$ 
Obesity and the Risks Associated with TKA Baghbani-Naghadehi et al.

Table 1 Patients characteristics by body mass index (BMI) group; $n=15,151$

\begin{tabular}{|c|c|c|c|c|c|c|}
\hline & \multicolumn{6}{|c|}{ BMI groups $\left(\mathrm{kg} / \mathrm{m}^{2}\right)^{a}$} \\
\hline & Normal (\%) & Overweight (\%) & $\begin{array}{l}\text { Obese } \\
\text { class I (\%) }\end{array}$ & $\begin{array}{l}\text { Obese } \\
\text { class II (\%) }\end{array}$ & $\begin{array}{l}\text { Obese } \\
\text { class III (\%) }\end{array}$ & $p$-Value \\
\hline Total number $(n)$ & 1,240 & 4,189 & 4,541 & 2,839 & 2,342 & \\
\hline \multicolumn{7}{|l|}{ Age group (y) } \\
\hline$<50$ & 2.0 & 1.3 & 2.0 & 2.6 & 4.1 & $<0.001$ \\
\hline $50-59$ & 16.4 & 15.8 & 19.7 & 23.0 & 32.2 & $<0.001$ \\
\hline $60-69$ & 29.4 & 36.0 & 38.5 & 44.4 & 45.4 & $<0.001$ \\
\hline $70-79$ & 31.3 & 33.4 & 30.5 & 25.4 & 16.2 & $<0.001$ \\
\hline$\geq 80$ & 21.0 & 13.6 & 9.4 & 4.6 & 2.1 & $<0.001$ \\
\hline \multicolumn{7}{|l|}{ Sex } \\
\hline Male & 30.5 & 44.6 & 43.7 & 35.4 & 28.6 & $<0.001$ \\
\hline Female & 69.5 & 55.4 & 56.3 & 64.6 & 71.4 & $<0.001$ \\
\hline \multicolumn{7}{|l|}{ Comorbidities } \\
\hline Diabetes & 10.1 & 10.0 & 13.4 & 15.7 & 20.9 & $<0.001$ \\
\hline Mental health & 11.1 & 8.3 & 8.4 & 8.0 & 10.1 & $<0.001$ \\
\hline Cardiac disease & 0.7 & 0.8 & 0.8 & 0.7 & 0.8 & 0.871 \\
\hline Pulmonary disease & 0.2 & 0.1 & 0.2 & 0.2 & 0.3 & 0.242 \\
\hline Blood circulatory/clotting & 0.2 & 0.2 & 0.2 & 0.1 & 0.1 & 0.030 \\
\hline Smoker & 7.2 & 7.4 & 8.6 & 7.8 & 8.2 & 0.002 \\
\hline Alcohol abuse & 2.8 & 2.5 & 2.2 & 1.9 & 2.2 & $<0.001$ \\
\hline \multicolumn{7}{|l|}{ Complications } \\
\hline Readmission/30 days & 4.5 & 3.7 & 3.6 & 3.3 & 4.3 & $<0.001$ \\
\hline Pulmonary embolism & 0.7 & 1.3 & 1.7 & 1.7 & 1.9 & $<0.001$ \\
\hline Deep wound infection & 0.7 & 0.5 & 0.6 & 0.8 & 1.5 & $<0.001$ \\
\hline Myocardial infarction & 0.3 & 0.4 & 0.3 & 0.3 & 0.1 & $<0.001$ \\
\hline Ileus & 0.2 & 0.2 & 0.3 & 0.4 & 0.3 & 0.070 \\
\hline Pneumonia & 0.2 & 0.2 & 0.3 & 0.3 & 0.1 & 0.020 \\
\hline Deep vein thrombosis & 0.1 & 0.2 & 0.1 & 0.1 & 0.0 & 0.060 \\
\hline Gastrointestinal bleed & 0.1 & 0.0 & 0.2 & 0.2 & 0.1 & 0.030 \\
\hline Cerebrovascular accident & 0.1 & 0.0 & 0.0 & 0.0 & 0.0 & 0.040 \\
\hline
\end{tabular}

Note: $p$-Values are comparing the percentage of each row among different BMI groups.

${ }^{a}$ Normal weight $\left(B M I \leq 24.99 \mathrm{~kg} / \mathrm{m}^{2}\right)$, overweight $\left(\mathrm{BMI}=25-29.99 \mathrm{~kg} / \mathrm{m}^{2}\right)$, obese class I $\left(\mathrm{BMI}=30-34.99 \mathrm{~kg} / \mathrm{m}^{2}\right)$, obese class II $(\mathrm{BMI}=35-$ $\left.39.99 \mathrm{~kg} / \mathrm{m}^{2}\right)$, and obese class III (BMI $\left.\geq 40 \mathrm{~kg} / \mathrm{m}^{2}\right)$.

years) and a lower proportion of older patients ( $\geq 80$ years) compared with the normal BMI group. This suggests that patients with obesity generally receive TKA at a younger age. Patients with obesity class III were on average 7.5 years younger than the group with normal BMI. Other studies have similarly reported that patients with obesity and severe $\mathrm{OA}$ were younger. ${ }^{12,16,17}$ For example, Dowsey and colleagues ${ }^{16}$ found that patients with severe obesity who had undergone TKA were 6 years younger than patients without obesity. Taken together, these results may suggest that obesity accelerates the progression of $\mathrm{OA},{ }^{9}$ resulting in patients with obesity reaching end-stage knee OA earlier. Consequently, patients with obesity seek surgical solutions at a younger age compared with patients with normal BMIs. It is well known that females require TKA more frequently than males. ${ }^{12}$ In our cohort of patients who underwent TKA, there was also a higher proportion of females than males across all BMI groups, with obese class-III group having the highest proportion. It is noteworthy that females tend to delay joint replacement and only consider TKA when they are in extreme need because they are more concerned about the surgical risk and being a burden on the family. ${ }^{18}$ Delaying surgery may result in decreased physical activity (because of pain) and resultant weight gain which may explain why there is an even higher proportion of females in the obese class-III group. ${ }^{18}$

Previous studies have shown that obesity increases the risk of adverse events after TKA. ${ }^{11-13}$ However, defining 
Obesity and the Risks Associated with TKA Baghbani-Naghadehi et al.

Table 2 Odds ratio for different BMI groups versus normal BMI group for comorbidities and complications

\begin{tabular}{|c|c|c|c|c|c|c|c|c|}
\hline & \multicolumn{2}{|c|}{$\begin{array}{l}\text { Overweight versus normal } \\
\text { BMI }\end{array}$} & \multicolumn{2}{|c|}{$\begin{array}{l}\text { Obese class I versus normal } \\
\text { BMI }\end{array}$} & \multicolumn{2}{|c|}{$\begin{array}{l}\text { Obese class II versus nor- } \\
\text { mal BMI }\end{array}$} & \multicolumn{2}{|c|}{$\begin{array}{l}\text { Obese class III versus nor- } \\
\text { mal BMI }\end{array}$} \\
\hline & OR (95\% Cl) & $p$-Value & OR $(95 \% \mathrm{Cl})$ & $p$-Value & OR $(95 \% \mathrm{Cl})$ & $p$-Value & OR $(95 \% \mathrm{Cl})$ & $p$-Value \\
\hline \multicolumn{9}{|l|}{ Comorbidities $^{\mathrm{a}}$} \\
\hline Diabetes & $0.96(0.77-1.19)$ & 0.68 & $1.44(1.17-1.78)$ & $<0.001$ & $1.99(1.60-2.48)$ & $<0.001$ & $3.38(2.70-4.10)$ & $<0.001$ \\
\hline $\begin{array}{l}\text { Mental } \\
\text { health }\end{array}$ & $0.83(0.67-1.02)$ & 0.08 & $0.85(0.69-1.05)$ & 0.13 & $0.81(0.64-1.02)$ & 0.07 & $0.94(0.74-1.19)$ & 0.72 \\
\hline $\begin{array}{l}\text { Cardiac } \\
\text { disease }\end{array}$ & $1.18(0.58-2.48)$ & 0.66 & $1.22(0.58-2.57)$ & 0.60 & $1.33(0.59-2.99)$ & 0.48 & $1.95(0.84-4.29)$ & 0.14 \\
\hline \multicolumn{9}{|l|}{ Complications $^{\mathrm{b}}$} \\
\hline $\begin{array}{l}\text { Blood } \\
\text { transfusion }\end{array}$ & $0.77(0.64-0.93)$ & $<0.001$ & $0.61(0.50-0.74)$ & 0.006 & $0.53(0.42-0.66)$ & $<0.001$ & $0.38(0.29-0.49)$ & $<0.001$ \\
\hline $\begin{array}{l}\text { Pulmonary } \\
\text { embolism }\end{array}$ & $1.95(0.96-3.97)$ & 0.07 & $2.73(1.37-5.51)$ & $<0.001$ & $2.77(1.34-5.71)$ & $<0.001$ & $3.62(1.37-7.56)$ & $<0.001$ \\
\hline $\begin{array}{l}\text { Deep wound } \\
\text { infection }\end{array}$ & $0.58(0.26-1.29)$ & 0.18 & $0.74(0.34-1.59)$ & 0.44 & $1.15(0.53-2.52)$ & 0.73 & $2.25(1.07-4.85)$ & 0.04 \\
\hline $\begin{array}{l}\text { Readmission/ } \\
30 \text { days }\end{array}$ & $0.89(0.65-1.23)$ & 0.51 & $0.90(0.66-1.24)$ & 0.53 & $0.93(0.65-1.31)$ & 0.67 & $1.27(0.89-1.99)$ & 0.12 \\
\hline
\end{tabular}

Abbreviations: $\mathrm{BMI}$, body mass index; $\mathrm{Cl}$, confidence intervals; OR, odd ratios.

Note: Normal weight $\left(\mathrm{BMI} \leq 24.99 \mathrm{~kg} / \mathrm{m}^{2}\right)$, overweight $\left(\mathrm{BMI}=25-29.99 \mathrm{~kg} / \mathrm{m}^{2}\right)$, obese class I $\left(\mathrm{BMI}=30-34.99 \mathrm{~kg} / \mathrm{m}^{2}\right)$, obese class II $(\mathrm{BMI}=35-$ $\left.39.99 \mathrm{~kg} / \mathrm{m}^{2}\right)$, and obese class III (BMI $\left.\geq 40 \mathrm{~kg} / \mathrm{m}^{2}\right)$.

ORs are generated from multiple logistic regression and are adjusted for other comorbidities/complications and demographic info.

${ }^{\mathrm{a}}$ ORs for blood clots, pulmonary disease, and dementia were not generated due to lower or zero frequency for some BMI groups.

${ }^{b}$ ORs for myocardial infarction, lleus, pneumonia, deep vein thrombosis, gastrointestinal bleed, and cerebrovascular accident were not generated due to lower or zero frequency for some BMI groups.

Table 3 Odds ratio of having peri/postoperative complications given a certain comorbidity

\begin{tabular}{|c|c|c|c|c|c|c|c|c|}
\hline \multirow[b]{3}{*}{ Comorbidities } & \multicolumn{8}{|l|}{ Complications } \\
\hline & \multicolumn{2}{|l|}{ Blood transfusion } & \multicolumn{2}{|c|}{ Readmission/30 days } & \multicolumn{2}{|c|}{ Pulmonary embolism } & \multicolumn{2}{|c|}{ Deep wound infection } \\
\hline & OR $(95 \% \mathrm{Cl})$ & $p^{\mathrm{b}}$ & OR (95\% Cl) & $p$ & OR (95\% Cl) & $p$ & OR $(95 \% \mathrm{Cl})$ & $p$ \\
\hline Diabetes & $1.76(1.52-2.05)$ & $<0.001$ & $1.60(1.30-1.98)$ & $<0.001$ & $0.78(0.53-1.16)$ & 0.23 & $0.72(0.41-1.26)$ & 0.25 \\
\hline Cardiac disease & $3.07(1.98-4.76)$ & $<0.001$ & $1.78(0.92-3.47)$ & 0.09 & $4.89(2.47-9.70)$ & $<0.001$ & $N C^{a}$ & NC \\
\hline $\begin{array}{l}\text { Pulmonary } \\
\text { disease }\end{array}$ & $2.20(0.89-5.44)$ & 0.08 & $0.43(0.06-3.30)$ & 0.42 & $7.51(2.46-2.29)$ & $<0.001$ & NC & NC \\
\hline $\begin{array}{l}\text { Circulatory/ } \\
\text { clotting disorder }\end{array}$ & $7.02(2.88-17.08)$ & $<0.001$ & $2.85(0.81-9.99)$ & 0.10 & NC & NC & NC & NC \\
\hline Mental health & $1.62(1.36-1.93)$ & $<0.001$ & $2.12(1.69-2.67)$ & $<0.001$ & $1.15(0.74-1.78)$ & 0.52 & $1.34(0.74-2.44)$ & 0.33 \\
\hline Alcohol abuse & $1.47(1.02-2.11)$ & 0.04 & $2.07(1.39-3.09)$ & $<0.001$ & $0.41(0.10-1.70)$ & 0.22 & $1.66(0.70-3.94)$ & 0.25 \\
\hline Smoker & $1.37(1.12-1.67)$ & 0.002 & $1.65(1.28-2.14)$ & $<0.001$ & $1.31(0.84-2.04)$ & 0.23 & $1.54(0.88-2.69)$ & 0.13 \\
\hline
\end{tabular}

Abbreviations: $\mathrm{Cl}$, confidence intervals; $\mathrm{NC}$, not converged; OR, odd ratio.

Note: Results are from multivariate logistic regression to find the association between each of the complications and comorbidities adjusting for demographic information.

aLogistic regression to find out the association between dementia, myocardial infarction, Ileus, pneumonia, deep vein thrombosis did not converge due to lower or zero frequency.

${ }^{\mathrm{b}} \mathrm{p}=$ significance level.

obesity simply based on BMI below or above $30 \mathrm{~kg} / \mathrm{m}^{2}$ leaves out critical information because the degree of obesity also plays an important role in determining the risk of perioperative/postoperative complications. There is limited information about the association between different grades of obesity, categorized according to WHO classification, and TKA complications in the literature. In our study, we catego- rized patients based on BMI using WHO classification to evaluate the effect of different BMI levels on complications following TKA. Results of the current study show that patients with higher BMI, independent of other factors, were more likely to have a pulmonary embolism, deep wound infection, and be readmitted to the hospital within 30 days of discharge. Besides obesity, other comorbidities 
were also associated with TKA complications. Patients with comorbidities were more likely to have a blood transfusion, infection, pulmonary embolism, and readmission.

Previous studies have similarly reported increased probability of pulmonary embolism in patients with higher BMI

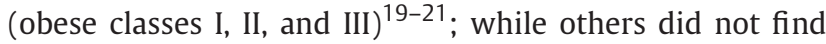
obesity to be an independent risk factor for pulmonary embolism. ${ }^{22,23}$ The variability of research findings in this area may be due to different cut-offs used to define obesity, as well as inadequate adjustments for the possible confounding factors. Other studies similarly reported that the obese class-III group compared with BMI normal group was more likely to have wound-related complications. ${ }^{20,21,24}$ The higher amount of fat deposition around the knee may be related to delay in wound closure and healing, longer operative times, poor vascularization of fatty tissues, and a weakened immune response. ${ }^{20}$ Other studies report that the higher risk of wound-related complications in the obese class-III group may be related to the presence of diabetes. ${ }^{21}$ However, we did not find any association between diabetes and wound-related complications.

Of note, further detailed analysis revealed that the normal BMI and obese class-III groups were significantly more likely $(p<0.001)$ to be readmitted to the hospital within 30 days of discharge compared with the other BMI groups (classes I, II, and overweight). Previous studies have also suggested that readmission has a $\mathbf{U}$-shaped relationship with BMI, and those with very low or very high BMI had a higher risk of readmission. ${ }^{20,25}$ The higher risk of readmission in BMI class III could be due to higher rates of comorbidities and wound-related infections associated with obesity. ${ }^{20,26,27}$ Whereas the higher risk of readmission in the normal BMI group could be related to higher rates of blood transfusion, mental health issues, and lower length of hospital stays. ${ }^{20,26,27}$ We also found that the likelihood of blood transfusion was lower in patients with higher BMI which is in line with other studies. $^{20,28}$ In patients with higher BMIs, the actual percentage of blood volume lost following TKA might be lower due to the higher blood volume in these patients ${ }^{29}$ which eventually leads to lower rates of blood transfusion compared with patients with normal BMI quality of life following TKA.

Besides obesity, other comorbidities are also independent predictors for postoperative complications. We found a higher likelihood of pulmonary embolism in patients with cardiac and pulmonary disease. A higher likelihood of readmission was detected in patients with diabetes, mental health problems, alcohol abuse, or current smokers. The higher likelihood of blood transfusion was observed in all of the comorbidities except pulmonary disease. These results are similar to previous research. ${ }^{26,30-34}$ However, some studies did not find an association between complications and comorbidities including diabetes, ${ }^{35,36}$ cardiac disease, mental health, ${ }^{37}$ and smoking. ${ }^{38,39}$ The discrepancy in results could be due to sample size, severity of the disease, and lack of analysis of other potential confounding variables including age, sex, and number of medical comorbidities. Altogether, our results support the finding that obesity along with other comorbidities is an independent risk factor for adverse events following TKA; however, the level of the risk depends on the type of complication. As Bone and Joint Health Strategic Clinical Network (BJHSCN) recommended no specific BMI value is being proposed as a threshold to consider patients for TKA. ${ }^{40}$ Since risks associated with the surgery may outweigh benefits and health outcomes in patients with obesity, an individualized preoperative optimization program is being recommended for patients with obesity undergoing TKA. ${ }^{41}$

\section{Strength and Limitations}

Our study included a large dataset routinely checked by $\mathrm{ABJHI}$ for quality assurance. These data were collected from the whole province which makes our results more generalizable. We categorized patients into five groups based on BMI according to WHO classification which allowed us to demonstrate a clear relationship between BMI group with complications and comorbidities. Certain aspects of our study methodology should be emphasized. We only examined perioperative and postoperative events within 30 days of TKA. Some of the potential postoperative complications may occur after this time period, and our study did not capture those events. We were not able to report odd ratios for some of the parameters due to very low or zero event rates. There was a lack of information on the number of deaths in the dataset. Incomplete data collection for some variables such as weight and height records, length of stay in hospital, and lack of detailed clinical information including presurgical OA severity diagnosis, and the number of deaths that occurred in the cohort are all valid concerns. Moreover, we used BMI as a measure of obesity; however, BMI does not provide information about body composition and fat distribution. ${ }^{42}$ Further studies are needed to elucidate the association between body composition and fat distribution using sophisticated methods such as dual-energy X-ray absorptiometry (DEXA) with complications in patients with TKA. It is also noteworthy that obesity definition has been changed in the newly released obesity guideline to "a chronic disease characterized by excessive or abnormal body fat that impairs health." 11,43 The new guideline recommended use of the Edmonton Obesity Staging System ${ }^{41}$ as a complementary measure for BMI. Future studies can explore the association between obesity staging and surgery outcomes. These recognized limitations are inherent to retrospective studies of administrative databases and could potentially be improved through prospective data collection.

\section{Conclusion}

This study added to the literature on the association between obesity and other major comorbidities on short-term complications in patients who underwent TKA. Overall, we demonstrated that the patients in the obese cohort were younger, included more females, and had a higher incidence of major comorbidities. With increase in BMI, the likelihood of having pulmonary embolism and deep wound infection were increased. The normal BMI group had the highest likelihood of 
blood transfusion. There was also a high association between major comorbidities with peri/postoperative complications. Obesity, independent of other comorbidities, places patients at increased risk of adverse events after TKA, though the level of risk depends on the severity of obesity and the type of complication. These findings may be used by patients and care providers to educate patients in higher BMI groups about the risks and benefits of an elective procedure.

\section{Ethical Approval and Consent to Participate}

The study was approved by the University of Alberta Health Research Ethics Board (ID: Pro00053754), and permission was obtained to extract data from the Alberta Bone and Joint Health Institute (ABJHI) registry. Because of the anonymous nature of the data, the requirement for individual patient written informed consent was waived.

\section{Funding \\ None.}

\section{Conflict of Interest}

None declared.

\section{References}

1 Obesity: preventing and managing the global epidemic. Report of a WHO consultation. World Health Organ Tech Rep Ser 2000;894: i-xii, 1-253

2 Haslam DW, James WP. Obesity. Lancet 2005;366(9492): 1197-1209

3 Singh GM, Danaei G, Farzadfar F, et al; Global Burden of Metabolic Risk Factors of Chronic Diseases Collaborating Group; Asia-Pacific Cohort Studies Collaboration (APCSC) Diabetes Epidemiology: Collaborative analysis of Diagnostic criteria in Europe (DECODE) Emerging Risk Factor Collaboration (ERFC) Prospective Studies Collaboration (PSC) The age-specific quantitative effects of metabolic risk factors on cardiovascular diseases and diabetes: a pooled analysis. PLoS One 2013;8(07):e65174

4 Workgroup of the American Association of Hip and Knee Surgeons Evidence Based Committee. Obesity and total joint arthroplasty: a literature based review. J Arthroplasty 2013;28(05):714-721

5 Apold H, Meyer HE, Nordsletten L, Furnes O, Baste V, Flugsrud GB. Weight gain and the risk of knee replacement due to primary osteoarthritis: a population based, prospective cohort study of 225,908 individuals. Osteoarthritis Cartilage 2014;22(05): 652-658

6 Dere D, Paker N, Soy Buğdayci D, Tekdöş Demircioğlu D. Effect of body mass index on functional recovery after total knee arthroplasty in ambulatory overweight or obese women with osteoarthritis. Acta Orthop Traumatol Turc 2014;48(02):117-121

7 McQueen DA, Long MJ, Algotar AM, Schurman JR II, Bangalore VG. The effect of obesity on quality-of-life improvement after total knee arthroplasty. Am J Orthop 2007;36(08):E117-E120, E127

8 Odum SM, Springer BD, Dennos AC, Fehring TK. National obesity trends in total knee arthroplasty. J Arthroplasty 2013;28 (8, suppl):148-151

9 Salih S, Sutton P. Obesity, knee osteoarthritis and knee arthroplasty: a review. BMC Sports Sci Med Rehabil 2013;5(01):25

10 Vasarhelyi EM, MacDonald SJ. The influence of obesity on total joint arthroplasty. J Bone Joint Surg Br 2012;94(11, suppl A): 100-102

11 Vulcano E, Lee YY, Yamany T, Lyman S, Valle AG. Obese patients undergoing total knee arthroplasty have distinct preoperative characteristics: an institutional study of 4718 patients. J Arthroplasty 2013;28(07):1125-1129

12 Werner BC, Evans CL, Carothers JT, Browne JA. Primary total knee arthroplasty in super-obese patients: dramatically higher postoperative complication rates even compared to revision surgery. J Arthroplasty 2015;30(05):849-853

13 Wallace G, Judge A, Prieto-Alhambra D, de Vries F, Arden NK, Cooper C. The effect of body mass index on the risk of postoperative complications during the 6 months following total hip replacement or total knee replacement surgery. Osteoarthritis Cartilage 2014;22(07):918-927

14 Wright JG, Coyte P, Hawker G, et al. Variation in orthopedic surgeons' perceptions of the indications for and outcomes of knee replacement. CMAJ 1995;152(05):687-697

15 Kremers HM, Visscher SL, Kremers WK, Naessens JM, Lewallen DG. The effect of obesity on direct medical costs in total knee arthroplasty. J Bone Joint Surg Am 2014;96(09):718-724

16 Dowsey MM, Liew D, Stoney JD, Choong PF. The impact of preoperative obesity on weight change and outcome in total knee replacement: a prospective study of 529 consecutive patients. J Bone Joint Surg Br 2010;92(04):513-520

17 Wolford ML, Palso K, Bercovitz A. Hospitalization for total hip replacement among inpatients aged 45 and over: United States, 2000-2010. NCHS Data Brief 2015;(186):1-8

18 Hawker GA, Wright JG, Coyte PC, et al. Differences between men and women in the rate of use of hip and knee arthroplasty. N Engl J Med 2000;342(14):1016-1022

19 Maltenfort M. CORR Insights: is obesity associated with increased risk of deep vein thrombosis or pulmonary embolism after hip and knee arthroplasty? A large database study. Clin Orthop Relat Res 2019;477(03):533-535

20 George J, Piuzzi NS, Ng M, Sodhi N, Khlopas AA, Mont MA. Association between body mass index and thirty-day complications after total knee arthroplasty. J Arthroplasty 2018;33(03): 865-871

21 Ward DT, Metz LN, Horst PK, Kim HT, Kuo AC. Complications of morbid obesity in total joint arthroplasty: risk stratification based on BMI. J Arthroplasty 2015;30(9, suppl):42-46

22 Andrew JG, Palan J, Kurup HV, Gibson P, Murray DW, Beard DJ. Obesity in total hip replacement. J Bone Joint Surg Br 2008;90 (04):424-429

23 Friedman RJ, Hess S, Berkowitz SD, Homering M. Complication rates after hip or knee arthroplasty in morbidly obese patients. Clin Orthop Relat Res 2013;471(10):3358-3366

24 Patel VP, Walsh M, Sehgal B, Preston C, DeWal H, Di Cesare PE. Factors associated with prolonged wound drainage after primary total hip and knee arthroplasty. J Bone Joint Surg Am 2007;89 (01):33-38

25 Thornqvist C, Gislason GH, Køber L, Jensen PF, Torp-Pedersen C, Andersson C. Body mass index and risk of perioperative cardiovascular adverse events and mortality in 34,744 Danish patients undergoing hip or knee replacement. Acta Orthop 2014;85(05): 456-462

26 Ali AM, Loeffler MD, Aylin P, Bottle A. Predictors of 30-day readmission after total knee arthroplasty: analysis of 566,323 procedures in the United Kingdom. J Arthroplasty 2019;34(02): 242-248.e1

27 Prohaska MG, Keeney BJ, Beg HA, et al. Preoperative body mass index and physical function are associated with length of stay and facility discharge after total knee arthroplasty. Knee 2017;24(03): 634-640

28 Frisch N, Wessell NM, Charters M, et al. Effect of body mass index on blood transfusion in total hip and knee arthroplasty. Orthopedics 2016;39(05):e844-e849

29 Walsh M, Preston C, Bong M, Patel V, Di Cesare PE. Relative risk factors for requirement of blood transfusion after total hip arthroplasty. J Arthroplasty 2007;22(08):1162-1167 
Obesity and the Risks Associated with TKA Baghbani-Naghadehi et al.

30 Danninger T, Rasul R, Poeran J, et al. Blood transfusions in total hip and knee arthroplasty: an analysis of outcomes. ScientificWorldJournal 2014;2014:623460

31 Rhee C, Lethbridge L, Richardson G, Dunbar M. Risk factors for infection, revision, death, blood transfusion and longer hospital stay 3 months and 1 year after primary total hip or knee arthroplasty. Can J Surg 2018;61(03):165-176

$32 \mathrm{Gu}$ A, Wei C, Robinson HN, et al. Postoperative complications and impact of diabetes mellitus severity on revision total knee arthroplasty. J Knee Surg 2020;33(03):228-234

33 Singh JA. Smoking and outcomes after knee and hip arthroplasty: a systematic review. J Rheumatol 2011;38(09):1824-1834

34 Schairer WW, Sing DC, Vail TP, Bozic KJ. Causes and frequency of unplanned hospital readmission after total hip arthroplasty. Clin Orthop Relat Res 2014;472(02):464-470

35 Bernatz JT, Tueting JL, Anderson PA. Thirty-day readmission rates in orthopedics: a systematic review and meta-analysis. PLoS One 2015;10(04):e0123593

36 Adams AL, Paxton EW, Wang JQ et al. Surgical outcomes of total knee replacement according to diabetes status and glycemic control, 2001 to 2009. J Bone Joint Surg Am 2013;95(06):481-487
37 Workman KK, Angerett N, Lippe R, Shin A, King S. Thirty-day unplanned readmission after total knee arthroplasty at a teaching community hospital: rates, reasons, and risk factors. J Knee Surg 2020;33(02):206-212

38 Matharu GS, Mouchti S, Twigg S, et al. The effect of smoking on outcomes following primary total hip and knee arthroplasty: a population-based cohort study of 117,024 patients. Acta Orthop 2019;90(06):559-567

39 Ali AM, Loeffler MD, Aylin P, Bottle A. Factors associated with 30day readmission after primary total hip arthroplasty: analysis of 514455 procedures in the UK National Health Service. JAMA Surg 2017;152(12):e173949

40 Kania-Richmond A, Werle J, Robert J. Bone and Joint Health Strategic Clinical Network. CMAJ 2019;191(suppl):S10-S12

41 Wharton S, Lau DCW, Vallis M, et al. Obesity in adults: a clinical practice guideline. CMAJ 2020;192(31):E875-E891

42 Shah NR, Braverman ER. Measuring adiposity in patients: the utility of body mass index (BMI), percent body fat, and leptin. PLoS One 2012;7(04):e33308

43 Sharma AM, Kushner RF. A proposed clinical staging system for obesity. Int J Obes 2009;33(03):289-295 